encountered in television, video games, computer screens, motion pictures, advertising displays, rock concerts, theater, opera, dance halls, nightclubs, and architectural materials. To reduce the risk of provoking seizures, the following recommendations were made for the design of flashing images or regular patterns: Potential hazards to be avoided include 1) a flash of luminance $>20 \mathrm{~cd} / \mathrm{m} 2$, at a frequency $>3 \mathrm{~Hz}$, in $25 \%$ of screen area at viewing distance; 2) a transition to and from saturated red; 3 ) a striped pattern, with more than 5 lightdark pairs of stripes; 4) stripes that change direction, oscillate, flash, or reverse in contrast; and 5) a pattern of $>8$ pairs of stripes that is unchanging or drifting in one direction. (Harding G, Wilkins AJ, Erba G et al. Photic- and pattern-induced seizures: Expert consensus of the Epilepsy Foundation of America Working Group. Epilepsia September 2005;46:1423-1425). (Reprints: Dr RS Fisher, Stanford Medical Center, Room A343, 300 Pasteur Drive, Stanford, CA 94305).

COMMENT. Visually induced seizures may be generalized or focal, idiopathic or syniptomatic, or represent a pure, reflex photosensitive epilepsy (Guerrini R et al. Epilepsia 2004;45 (Suppl 1):14-18; Ped Neur Briefs Jan 2004;18:7). For further articles on photosensitive seizures, see Ped Neur Briefs 2004;18:36-37.

The background information obtained from a review of the literature and used by the EFA for their consensus recommendations is outlined by Fisher RS et al. Epilepsia Sept 2005;46:1426-1441.

Reflex seizures in children with malformations of cortical development tend to be refractory to anticonvulsant medications but may respond to surgical resection of focal lesions. (Palmini A et al. Epilepsia 2005;46:1224-1234).

\title{
EFFECT OF COMBINED KETOGENIC DIET AND VALPROATE TREATMENT FOR INTRACTABLE SEIZURES
}

The safety and tolerability of ketogenic diet (KGD) and valproate (VPA) cotherapy in the treatment of intractable seizures were evaluated retrospectively at the Massachusetts General Hospital, Boston. The ages of a total of 71 patients were 7 months to 20 years (mean, 7 years). All had received the KGD, and 24 were treated concomitantly with VPA. Two patients $(2.8 \%)$ developed pancreatitis after 4 months on the KGD alone. Adverse events affecting patients equally in the KGD/VPA and non-VPA groups included symptomatic acidosis $(39.4 \%)$, nausea and vomiting $(23.9 \%)$, hypertriglyceridemia $(21.1 \%)$, infections (eg otitis media, URI) in $21 \%$, lethargy (18.3\%), and behavioral abnormalities and irritability (15.5\%). Renal calculi affected $6.4 \%$ of the KGD alone group. Elevations in liver function tests occurred in 2 patients taking VPA cotherapy. Carnitine supplements were given to 19 patients on the diet, and no patient reported symptoms of carnitine deficiency. Treatment was continued at 1 year in 32 patients, 11 taking the combined KGD and VPA therapy. Reductions in seizure frequency at 1 year were $47 \%$ with $>90 \%$ reduction, $25 \%$ with $50-90 \%$ reduction, and $29 \%$ with $<50 \%$ reduction. Seizure control was not significantly different in the KGD and VPA cotherapy groups and was unrelated to the KGD fat to carbohydrate ratio. The majority received a ratio of $4: 1$ at initiation of the diet, 17 had ratios of 3.5-3.9:1, and 12, ratios of 3-3.4:1, fat to carbohydrate + protein. Anticonvulsant regimens were adjusted or eliminated during the trial of the KGD. The authors consider KGD and VPA cotherapy to be safe and effective in the management of refractory pediatric epilepsy. (Lyczkowski DA, 
Pfeiffer HH, Ghosh S, Thiele EA. Safety and tolerability of the ketogenic diet in pediatric epilepsy: Effects of valproate combination therapy. Epilepsia September 2005;46:15331538). (Reprints: Dr EA Thiele, Pediatric Epilepsy Program, Massachusetts General Hospital, 175 Cambridge St, Suite 340, Boston, MA 02114).

COMMENT. The authors' experience shows that concerns regarding possible adverse effects of cotherapy with the KGD and VPA in refractory epilepsy should not exclude a trial of the simultaneous use of these agents, with careful monitoring. Since seizure control was apparently not related to degree of ketosis in the above study, the introduction of the diet using the original Mayo Clinic regimen (with lower fat:carbohydrate ratios) rather than the Hopkins method of initiation (with a 4:1 ratio) should lower the incidence of adverse events and heighten the tolerability. (Millichap JG et al. Epilepsia 1964;5:239-255; Am J Dis Child 1964;107:593-604; Ped Neur Briefs Feb 2005;19:12-13).

In a trial of the KGD in 20 patients with Dravet syndrome (severe myoclonic epilepsy in infants), $10(77 \%)$ of the 13 children who remained on the diet at 1 year had achieved a $>75 \%$ reduction in seizures, and quality of life was improved. (Caraballo $\mathrm{RH}$ et al. Epilepsia Sept 2005;46:1539-1544).

\section{OMEGA-3 FATTY ACID SUPPLEMENTS FOR CHRONIC EPILEPSY}

Omega-3 fatty acid (FA) supplements (1g EPA and $0.7 \mathrm{~g}$ DHA daily) were used in the treatment of 58 patients with refractory epilepsy, in a 12-week double-blind, placebocontrolled trial conducted by researchers at the UCL Institute of Neurology, London, UK. In the first 6 weeks of treatment, a $50 \%$ reduction in seizures was obtained in 5 of 29 supplemented patients whereas none $(0 / 27)$ showed benefit with placebo $(\mathrm{P}=0.087)$. In the second 6 weeks, this apparent initial trend toward significant difference in seizure control was not sustained: $4 / 30$ in the supplemented group and 5/27 in placebo group showed reduction in seizure frequency. The need for intermittent therapy with diazepam did not differ between the two groups. Status epilepticus occurred in one patient in each group. FA supplements produced an expected increase in plasma EPA and DHA concentrations and a reciprocal fall in omega-6 arachidonic and linoleic acid concentrations. Antiepileptic drug levels were unaffected. (Yuen AWC, Sander JW, Fluegel D et al. Omega-3 fatty acid supplementation in patients with chronic epilepsy: a randomized trial. Epilepsy Behav September 2005;7:253-258). (Respond: Ley Sander. Fax: +44 1494 872699).

COMMENT. Experimental studies in animals have shown that EPA and DHA as well as omega-6 FA will raise seizure thresholds, and omega-3 FA will lower plasma inflammatory mediators, which may lead to reduction in seizure susceptibility (Bailey EE et al. Epilepsy Behav 2005;6:4-8). In a recent report of the benefits of fatty acid supplements in children with reading disabilities and ADHD, a combination of omega- 3 and - 6 FA was recommended (Richardson AJ et al. Pediatrics 2005;115:1360-1366; Ped Neur Briefs May $2005 ; 19: 33-34)$. Future trials of FA supplements in patients with refractory epilepsy should perhaps include both omega-3 and $-6 \mathrm{FA}$. 